\title{
UBE3C genetic variations as potent markers of nasal polyps in Korean asthma patients
}

\author{
Charisse Flerida A Pasaje ${ }^{1,5}$, Jeong-Hyun Kim ${ }^{1,5}$, Byung-Lae Park ${ }^{2}$, Jong-Sook Park ${ }^{3}$, Soo-Taek Uh ${ }^{3}$, \\ Mi-Kyeong Kim ${ }^{4}$, Choon-Sik Park ${ }^{3}$ and Hyoung Doo Shin ${ }^{1,2}$
}

The human ubiquitin protein ligase $E 3 C$ (UBE3C) regulates airway inflammatory responses and is hypothesized to be associated with the presence of nasal polyps in asthma-related diseases. A total of 24 UBE3C single-nucleotide polymorphisms (SNPs) were genotyped in a 467 Korean asthma cohort that was stratified into more homogenous phenotypes of 114 aspirinexacerbated respiratory disease subgroup and 353 aspirin-tolerant asthma (ATA) subjects. Association analysis revealed that 16 UBE3C SNPs were significantly associated with presence of nasal polyps in the overall asthma group $(P=0.0008$ and $P^{c o r r}=0.01$; odds ratio $\left.(O R)=0.60\right)$. The strength of association from 10 polymorphisms was increased in the ATA subgroup $(P=0.0002$ and $P$ orr $=0.003 ; O R=0.49)$. In addition, UBE3C_ht 1 was found to be consistently associated with nasal polyps in the overall asthmatics group $(P=0.006)$ and the ATA phenotype $\left(P=0.002 ; P^{c o r r}=0.02\right)$ via a codominant mechanism. Our findings provide evidence that variations in UBE3C are potent genetic markers of nasal polyps development in Korean asthmatics and may contribute novel insights into the clinical relevance and potential involvement of $U B E 3 C$ in respiratory deficiencies.

Journal of Human Genetics (2011) 56, 797-800; doi:10.1038/jhg.2011.104; published online 1 September 2011

Keywords: aspirin-exacerbated respiratory disease; haplotypes; nasal polyp; single-nucleotide polymorphism; UBE3C

\section{INTRODUCTION}

Nasal polyps are benign growth, which develop from chronic inflammation of the lateral wall of the nose and sinuses. ${ }^{1,2}$ Prevalence estimates of nasal polyps have been reported to be around $7-15 \%$ in aspirin-tolerant asthma (ATA) $)^{3}$ and $31-60 \%$ in aspirinexacerbated respiratory disease (AERD), ${ }^{4}$ a condition that is characterized by bronchial obstruction, nasal polyposis and aspirin hypersensitivity.

The homologous to the E6-AP carboxyl terminus-type ubiquitin protein ligase E3C (UBE3C) gene is crucial in the development and differentiation of lymphocytes, activation of T-cell tolerance, antigen presentation and immune invasion. ${ }^{5}$ In the protein proteolytic pathway, UBE3C assembles polyubiquitin chain by binding to E2 ubiquitin-conjugating enzyme and transferring activated ubiquitin moieties to Lys48 of the previously conjugated ubiquitin molecule. ${ }^{6}$ The ubiquitin-proteasome pathway facilitates activation of nuclear transcription factor $\kappa B, 7,8$ an important regulator of a large number of cellular processes, including inflammatory responses in airways. ${ }^{9-11}$
Furthermore, evidence of association between UBE3C polymorphisms and AERD have been revealed previously. ${ }^{12}$

This case-control analysis was carried out to investigate the association of UBE3C gene variations with presence of nasal polyps in Korean asthma patients.

\section{MATERIALS AND METHODS}

Study patients

A total of 467 asthma patients were recruited from Korean hospitals affiliated with the Asthma Genome Research Center. Evaluation of asthma and tests measuring total immunoglobulin $\mathrm{E}$, atopy and reaction to inhalant allergens were carried out as described previously. ${ }^{13,14}$ Nasal polyposis was diagnosed based on the presence of endoscopically visible polyps arising from the middle nasal meatus.

The patients were stratified further into 114 AERD (composed of 66 polyppositive cases and 48 polyp-negative controls) and 353 ATA subgroups (composed of 92 polyp-positive cases and 261 polyp-negative controls) based on the individual reaction to aspirin challenge that was performed according to previous methods. ${ }^{13}$ Aspirin-induced $\mathrm{FEV}_{1}$ decline (polyp-positive $=12.22$ vs polyp-negative $=6.78$ ) and positive history of aspirin intolerance (polyp-

${ }^{1}$ Department of Life Science, Sogang University, Seoul, Republic of Korea; ${ }^{2}$ Department of Genetic Epidemiology, SNP Genetics, Inc., Seoul, Republic of Korea; ${ }^{3}$ Genome Research Center for Allergy and Respiratory Diseases, Division of Allergy and Respiratory Medicine, Soonchunhyang University Bucheon Hospital, Bucheon, Republic of Korea and ${ }^{4}$ Department of Internal Medicine, College of Medicine, Chungbuk National University, Cheongju, Republic of Korea

${ }^{5}$ These authors contributed equally to this work.

Correspondence: Professor HD Shin, Department of Life Science, Sogang University, Seoul 121-742, Republic of Korea.

E-mail: hdshin@sogang.ac.kr

or Dr C-S Park, Genome Research Center for Allergy and Respiratory Diseases, Division of Allergy and Respiratory Medicine, Soonchunhyang University Bucheon Hospital, Bucheon 140-743, Republic of Korea.

E-mail: schalr@schmc.ac.kr

Received 21 June 2011; revised 4 August 2011; accepted 5 August 2011; published online 1 September 2011 
positive $=41.77$ vs polyp-negative $=15.53)$ were significantly different between cases and controls $(P<0.0001$; Table 1$)$. The protocols were approved by the institutional review board of the each hospital, and the study subjects provided written informed consent.

Table 1 Clinical profiles of the study subjects

\begin{tabular}{|c|c|c|c|}
\hline Clinical profile & $\begin{array}{l}\text { Polyp-positive } \\
\text { asthmatics }\end{array}$ & $\begin{array}{c}\text { Polyp-negative } \\
\text { asthmatics }\end{array}$ & $\mathrm{P}$-value \\
\hline Number of subjects $(n)$ & 158 & 309 & \\
\hline Age (year, mean (range)) & $46.24(17.93-76.86)$ & $47.00(15.40-77.88)$ & 0.56 \\
\hline Sex ( $n$, male/female) & $55 / 103$ & $100 / 209$ & 0.60 \\
\hline $\begin{array}{l}\text { Total smoker (current } \\
\text { smoker; ex-smoker) (\%) }\end{array}$ & $27.21(11.39 ; 15.82)$ & $27.83(11.33 ; 16.50)$ & 0.93 \\
\hline Body mass index $\left(\mathrm{kg} \mathrm{m}^{-2}\right)$ & $23.95 \pm 3.00$ & $24.53 \pm 3.51$ & 0.06 \\
\hline $\begin{array}{l}\% \text { Fall of } \mathrm{FEV}_{1} \text { by aspirin } \\
\text { provocation }\end{array}$ & $12.22 \pm 14.39$ & $6.78 \pm 11.46$ & $<0.0001$ \\
\hline Blood eosinophil (\%) & $6.92 \pm 6.23$ & $5.98 \pm 6.00$ & 0.12 \\
\hline PC20 methacholine $\left(\mathrm{mg} \mathrm{ml}^{-1}\right)$ & $5.83 \pm 8.87$ & $6.88 \pm 8.62$ & 0.23 \\
\hline Total IgE (IU ml-1) & $298.35 \pm 469.67$ & $368.39 \pm 654.01$ & 0.19 \\
\hline $\mathrm{FEV}_{1}(\%$ predicted $)$ & $89.67 \pm 15.76$ & $91.79 \pm 17.33$ & 0.18 \\
\hline FVC (\% predicted) & $89.02 \pm 12.65$ & $87.68 \pm 14.56$ & 0.30 \\
\hline Positive rate of skin test (\%) & 51.90 & 57.61 & 0.24 \\
\hline $\begin{array}{l}\text { Positive rate of aspirin } \\
\text { intolerance (\%) }\end{array}$ & 41.77 & 15.53 & $<0.0001$ \\
\hline
\end{tabular}

Abbreviations: FEV, forced expiratory volume; FVC, forced vital capacity.

Values are mean $\pm \mathrm{SE}$.

Significant values are shown in bold.
Genotyping of single-nucleotide polymorphisms and statistical analysis

Selection of single-nucleotide polymorphisms (SNPs), genotyping and statistical analyses were performed according to previous methods. ${ }^{13}$ Differences in the frequency distribution of $U B E 3 C$ variations were analyzed using logistic models controlling for age, sex, smoking status and atopy, including AERD status in the analysis of the overall asthma patients.

\section{RESULTS AND DISCUSSION}

Twenty-four UBE3C SNPs were successfully genotyped and showed a tight LD block in 467 asthma patients, similar to previous results. ${ }^{12}$ Three major haplotypes with frequencies over 0.05 were then included in the association analyses.

Logistic analysis in the overall asthmatics revealed that 21 SNPs achieved significance $(P=0.0008-0.009$; odds ratio $(\mathrm{OR})=0.60-0.67$; Table 2). The association signals of 16 SNPs remained robust ( $P^{\text {corr }}=0.01-0.05$; Table 1$)$ even after multiple testing corrections. Among the tested haplotypes, UBE3C_ht1 and UBE3C_ht2 were found to be nominally associated with nasal polyps development in asthmatics ( $P=0.006$ and 0.009 , respectively, $P^{\text {corr }}>0.05$; Table 2$)$.

To further characterize the association signals, more homogeneous asthma phenotypes composed of AERD and ATA subgroups were analyzed. Results of logistic analysis between the presence of nasal polyps in ATA patients and UBE3C polymorphisms revealed significant association signals for 10 SNPs even after multiple testing corrections $\quad\left(P=0.0002-0.01 ; \quad P^{\text {corr }}=0.003-0.009 ; \quad\right.$ OR $=0.49-0.54$;

Table 2 Association of UBE3C variations with nasal polyposis in the overall asthma patients

\begin{tabular}{|c|c|c|c|c|c|c|c|c|}
\hline SNP/haplotype & Position & $H W E^{*}$ & $\begin{array}{l}\text { Polyp-positive } \\
\qquad(n=158)^{a}\end{array}$ & $\begin{array}{l}\text { Polyp-negative } \\
\qquad(n=309)^{a}\end{array}$ & OR $(95 \% \mathrm{Cl})$ & $\mathrm{P} * *$ & $\mathrm{P}^{c o r r} * * *$ & Statistical power \\
\hline$r s 10949635 G>T$ & Promoter & 0.12 & 0.278 & 0.417 & $0.60(0.44-0.81)$ & 0.0008 & 0.01 & 60.40 \\
\hline$r s 7798816 A>G$ & Intron 1 & 0.21 & 0.380 & 0.510 & $0.65(0.49-0.87)$ & 0.003 & 0.04 & 68.09 \\
\hline$r s 3808316 G>C$ & Intron 1 & 0.21 & 0.380 & 0.510 & $0.65(0.49-0.87)$ & 0.003 & 0.04 & 68.09 \\
\hline$r s 733483 T>C$ & Intron 1 & 0.21 & 0.073 & 0.068 & $1.11(0.65-1.91)$ & 0.70 & - & 42.57 \\
\hline$r s 3802129 C>T$ & Intron 4 & 0.17 & 0.389 & 0.516 & $0.66(0.49-0.87)$ & 0.004 & 0.05 & 68.80 \\
\hline$r s 3802122 A>T$ & Intron 6 & 0.05 & 0.361 & 0.494 & $0.65(0.49-0.86)$ & 0.003 & 0.04 & 66.99 \\
\hline$r s 7802642 A>G$ & Intron 10 & 0.29 & 0.310 & 0.445 & $0.61(0.45-0.82)$ & 0.001 & 0.02 & 63.85 \\
\hline$r s 6955184 T>G$ & Intron 10 & 0.48 & 0.070 & 0.065 & $1.13(0.65-1.98)$ & 0.66 & - & 41.21 \\
\hline$r s 17837723 C>A$ & Intron 10 & 0.48 & 0.070 & 0.065 & $1.13(0.65-1.98)$ & 0.66 & - & 41.21 \\
\hline$r s 10271970 A>C$ & Intron 11 & 0.08 & 0.285 & 0.425 & $0.60(0.44-0.81)$ & 0.0008 & 0.01 & 60.92 \\
\hline rs6979947A>G & Intron 13 & 0.05 & 0.358 & 0.490 & $0.65(0.49-0.86)$ & 0.003 & 0.04 & 67.04 \\
\hline$r s 1636608 T>G$ & Intron 17 & 0.17 & 0.316 & 0.451 & $0.62(0.46-0.83)$ & 0.001 & 0.02 & 64.28 \\
\hline$r s 3802108 A>C$ & Intron 17 & 0.05 & 0.288 & 0.426 & $0.61(0.45-0.82)$ & 0.001 & 0.02 & 61.53 \\
\hline$r s 2301947 A>G$ & Intron 17 & 0.22 & 0.313 & 0.448 & $0.62(0.46-0.83)$ & 0.001 & 0.02 & 64.07 \\
\hline$r s 6960676 G>A$ & Intron 18 & 0.24 & 0.383 & 0.513 & $0.65(0.49-0.87)$ & 0.003 & 0.05 & 68.17 \\
\hline$r s 3779596 C>T$ & Intron 18 & 0.15 & 0.285 & 0.387 & $0.67(0.50-0.91)$ & 0.009 & $>0.05$ & 67.38 \\
\hline$r s 1182392 A>G$ & Intron 18 & 0.91 & 0.392 & 0.500 & $0.67(0.50-0.90)$ & 0.007 & $>0.05$ & 71.98 \\
\hline$r s 10271990 C>T$ & Intron 18 & 0.54 & 0.299 & 0.419 & $0.62(0.46-0.84)$ & 0.002 & 0.03 & 65.51 \\
\hline$r s 10228373 A>C$ & Intron 18 & 0.57 & 0.301 & 0.419 & $0.63(0.46-0.85)$ & 0.002 & 0.03 & 66.01 \\
\hline$r s 1182389 C>T$ & Intron 18 & 0.89 & 0.392 & 0.506 & $0.67(0.50-0.90)$ & 0.008 & $>0.05$ & 71.00 \\
\hline$r s 1182385 A>G$ & Intron 18 & 0.87 & 0.415 & 0.521 & $0.68(0.50-0.90)$ & 0.008 & $>0.05$ & 72.61 \\
\hline$r s 1182378 C>T$ & Intron 21 & 0.89 & 0.392 & 0.506 & $0.67(0.50-0.90)$ & 0.008 & $>0.05$ & 71.00 \\
\hline$r s 3757827 G>A$ & Intron 22 & 0.40 & 0.288 & 0.411 & $0.62(0.46-0.85)$ & 0.002 & 0.03 & 64.06 \\
\hline$r s 1182414 T>C$ & Intron 22 & 0.08 & 0.297 & 0.421 & $0.63(0.47-0.85)$ & 0.003 & 0.03 & 64.67 \\
\hline UBE3C_ht1 & & & 0.544 & 0.434 & $1.48(1.12-1.96)$ & 0.006 & $>0.05$ & \\
\hline UBE3C_ht2 & & & 0.218 & 0.327 & $0.65(0.47-0.90)$ & 0.009 & $>0.05$ & \\
\hline UBE3C_ht3 & & & 0.060 & 0.057 & $1.16(0.64-2.08)$ & 0.62 & - & \\
\hline
\end{tabular}

Abbreviations: AERD, aspirin-exacerbated respiratory disease; $\mathrm{Cl}$, confidence interval; HWE, Hardy-Weinberg equilibrium; OR, odds ratio; SNP, single-nucleotide polymorphism; UBE3C, ubiquitin protein ligase $E 3 C$.

${ }^{*} P$-values of deviation from HWE.

$* * P$-values at 0.05 level of significance adjusted for initial diagnosed age, sex, smoking status, atopy and AERD status under codominant model.

$* * * P$-values after multiple testing corrections (effective number of independent marker loci=13.2516).

${ }^{* * *} P$-values after multiple

Significant values are shown in bold. 
Table 3 Association of $U B E 3 C$ variations with nasal polyposis in ATA and AERD patients

\begin{tabular}{|c|c|c|c|c|c|c|c|c|c|c|}
\hline \multirow[b]{2}{*}{ SNP/haplotype } & \multicolumn{5}{|c|}{ ATA } & \multicolumn{5}{|c|}{$A E R D$} \\
\hline & $\begin{array}{c}\text { Polyp-positive } \\
\quad(\mathrm{n}=92)\end{array}$ & $\begin{array}{l}\text { Polyp-negative } \\
\quad(\mathrm{n}=261)\end{array}$ & OR $(95 \% \mathrm{Cl})$ & $P *$ & Pcorr ** & $\begin{array}{l}\text { Polyp-positive } \\
\qquad(\mathrm{n}=66)^{\mathrm{a}}\end{array}$ & $\begin{array}{l}\text { Polyp-negative } \\
\quad(\mathrm{n}=48)^{\mathrm{a}}\end{array}$ & OR $(95 \% \mathrm{Cl})$ & $P *$ & Pcorr** \\
\hline$r s 10949635 G>T$ & 0.283 & 0.437 & $0.52(0.36-0.75)$ & 0.0004 & 0.005 & 0.273 & 0.313 & $0.85(0.47-1.53)$ & 0.58 & - \\
\hline$r s 7798816 A>G$ & 0.413 & 0.521 & $0.65(0.46-0.91)$ & 0.01 & $>0.05$ & 0.333 & 0.448 & $0.63(0.36-1.10)$ & 0.10 & - \\
\hline$r s 3808316 G>C$ & 0.413 & 0.521 & $0.65(0.46-0.91)$ & 0.01 & $>0.05$ & 0.333 & 0.448 & $0.63(0.36-1.10)$ & 0.10 & - \\
\hline$r s 733483 T>C$ & 0.103 & 0.061 & $1.77(0.97-3.22)$ & 0.06 & - & 0.030 & 0.104 & $0.27(0.08-0.96)$ & 0.04 & $>0.05$ \\
\hline$r s 3802129 C>T$ & 0.418 & 0.529 & $0.64(0.46-0.91)$ & 0.01 & $>0.05$ & 0.348 & 0.448 & $0.66(0.38-1.14)$ & 0.14 & - \\
\hline$r s 3802122 A>T$ & 0.391 & 0.508 & $0.63(0.45-0.89)$ & 0.008 & $>0.05$ & 0.318 & 0.417 & $0.67(0.39-1.17)$ & 0.16 & - \\
\hline$r s 7802642 A>G$ & 0.310 & 0.464 & $0.52(0.36-0.74)$ & 0.0004 & 0.005 & 0.311 & 0.344 & $0.87(0.50-1.54)$ & 0.64 & - \\
\hline$r s 6955184 T>G$ & 0.098 & 0.059 & $1.71(0.93-3.14)$ & 0.08 & - & 0.030 & 0.094 & $0.27(0.07-1.00)$ & 0.05 & $>0.05$ \\
\hline$r s 17837723 C>A$ & 0.098 & 0.059 & $1.71(0.93-3.14)$ & 0.08 & - & 0.030 & 0.094 & $0.27(0.07-1.00)$ & 0.05 & $>0.05$ \\
\hline$r s 10271970 A>C$ & 0.283 & 0.446 & $0.49(0.34-0.71)$ & 0.0002 & 0.003 & 0.288 & 0.313 & $0.92(0.52-1.62)$ & 0.76 & - \\
\hline rs6979947A>G & 0.386 & 0.506 & $0.63(0.45-0.88)$ & 0.006 & $>0.05$ & 0.318 & 0.406 & $0.70(0.40-1.22)$ & 0.20 & - \\
\hline$r s 1636608 T>G$ & 0.321 & 0.469 & $0.54(0.38-0.77)$ & 0.0007 & 0.009 & 0.311 & 0.354 & $0.83(0.47-1.47)$ & 0.53 & - \\
\hline$r s 3802108 A>C$ & 0.288 & 0.446 & $0.51(0.36-0.74)$ & 0.0003 & 0.004 & 0.288 & 0.313 & $0.92(0.52-1.62)$ & 0.76 & - \\
\hline$r s 2301947 A>G$ & 0.315 & 0.467 & $0.53(0.37-0.75)$ & 0.0005 & 0.007 & 0.311 & 0.344 & $0.87(0.50-1.54)$ & 0.64 & - \\
\hline$r s 6960676 G>A$ & 0.413 & 0.527 & $0.63(0.45-0.89)$ & 0.009 & $>0.05$ & 0.341 & 0.438 & $0.67(0.39-1.17)$ & 0.16 & - \\
\hline$r s 3779596 C>T$ & 0.283 & 0.398 & $0.60(0.41-0.86)$ & 0.005 & $>0.05$ & 0.288 & 0.323 & $0.86(0.49-1.53)$ & 0.61 & - \\
\hline$r s 1182392 A>G$ & 0.397 & 0.511 & $0.61(0.43-0.87)$ & 0.006 & $>0.05$ & 0.386 & 0.438 & $0.80(0.46-1.39)$ & 0.42 & - \\
\hline$r s 10271990 C>T$ & 0.288 & 0.435 & $0.51(0.35-0.74)$ & 0.0004 & 0.005 & 0.315 & 0.333 & $0.92(0.53-1.61)$ & 0.78 & - \\
\hline$r s 10228373 A>C$ & 0.288 & 0.435 & $0.51(0.35-0.74)$ & 0.0004 & 0.005 & 0.318 & 0.333 & $0.93(0.53-1.62)$ & 0.79 & - \\
\hline$r s 1182389 C>T$ & 0.413 & 0.519 & $0.63(0.45-0.90)$ & 0.01 & $>0.05$ & 0.364 & 0.438 & $0.73(0.42-1.26)$ & 0.26 & - \\
\hline$r s 1182385 A>G$ & 0.424 & 0.531 & $0.63(0.44-0.89)$ & 0.01 & $>0.05$ & 0.402 & 0.469 & $0.75(0.44-1.29)$ & 0.30 & - \\
\hline$r s 1182378 C>T$ & 0.413 & 0.519 & $0.63(0.45-0.90)$ & 0.01 & $>0.05$ & 0.364 & 0.438 & $0.73(0.42-1.26)$ & 0.26 & - \\
\hline$r s 3757827 G>A$ & 0.277 & 0.431 & $0.49(0.33-0.72)$ & 0.0002 & 0.003 & 0.303 & 0.302 & $1.01(0.58-1.78)$ & 0.97 & - \\
\hline$r s 1182414 T>C$ & 0.288 & 0.439 & $0.52(0.36-0.75)$ & 0.0004 & 0.005 & 0.311 & 0.323 & $0.95(0.55-1.65)$ & 0.87 & - \\
\hline UBE3C_ht1 & 0.554 & 0.421 & $1.71(1.21-2.41)$ & 0.002 & 0.02 & 0.530 & 0.500 & 1.07 (0.64-1.79) & 0.79 & - \\
\hline UBE3C_ht2 & 0.234 & 0.345 & $0.58(0.40-0.86)$ & 0.006 & $>0.05$ & 0.197 & 0.229 & $0.84(0.44-1.57)$ & 0.58 & - \\
\hline UBE3C_ht3 & 0.087 & 0.054 & $1.66(0.88-3.13)$ & 0.12 & - & 0.023 & 0.073 & $0.28(0.06-1.22)$ & 0.09 & - \\
\hline
\end{tabular}

Abbreviations: AERD, aspirin-exacerbated respiratory disease; ATA, aspirin-tolerant asthma; $\mathrm{Cl}$, confidence interval; OR, odds ratio; SNP, single-nucleotide polymorphism; UBE3C, ubiquitin protein ligase E3C.

${ }^{*} P$-values at 0.05 level of significance adjusted for initial diagnosed age, sex, smoking status and atopy under codominant model.

$* * P$-values after multiple testing corrections (effective number of independent marker loci=13.2516).

ainor allele frequency.

Significant values are shown in bold.

Table 3). Although UBE3C_ht1 and UBE3C_ht2 were initially associated with nasal polyposis in ATA patients $(P=0.002$ and 0.006 , respectively, Table 3), only UBE3C_ht1 maintained significance under the strict criteria after multiple testing corrections $\left(P^{\mathrm{corr}}=0.02\right.$; Table 3). Furthermore, although several variants in UBE3C were previously identified to be risk factors of AERD, ${ }^{12}$ only nominal evidence of association were observed between $U B E 3 C$ polymorphisms and nasal polyposis among AERD patients in the current study $\left(P=0.04-0.05\right.$; $P^{\text {corr }}>0.05$; Table 3$)$, suggesting that the tested genetic variants may not affect polyp development in aspirin-hypersensitive asthmatics. The inconsistencies between the findings can be attributed to differences in the mechanisms underlying deficiencies of the upper and lower airways. In addition, although nasal polyps often co-occur with AERD, estimates of the prevalence of nasal polyposis are around $4 \%$ in the general population, suggesting that unidentified by-pathway and/or complex modulations might be involved in the generation of nasal polyps in AERD patients.

To determine whether $r s 10949635 G>T$ in the promoter region could be a putative binding site for regulators, we conducted in silico analysis using the Signal Scan program. ${ }^{15}$ However, the results failed to identify transcriptional regulators binding to the variant. In silico analysis using the EMBL-EBI splice site prediction was also performed to estimate the function of SNPs in intronic regions of UBE3C. None of the tested intronic SNPs, however, were predicted to be potential branch point sites for alternative splicing. Furthermore, using the
microRNA database, ${ }^{16}$ we failed to detect any microRNA sequences within the $U B E 3 C$ that could potentially repress gene translation.

The current study is limited by the exclusion of non-asthmatic controls with nasal polyps. Furthermore, after performing power calculations of single associations, we observed a $66.5 \%$ average statistical power to detect the effect sizes associated with the significant SNPs in all asthma subjects (Table 2). Although results from power calculations indicate insufficient sample size, a similar trend in the allelic frequencies of the analyzed $U B E 3 C$ variants was observed in Asian populations including Korean after comparing data from various ethnic groups using information from the International HapMap database (data not shown). In order to address these limitations and validate the findings, further replications using larger sample scales are required.

The current study shows for the first time that $U B E 3 C$ is an important genetic marker for onset of nasal polyposis in asthma patients. This finding may provide useful insights on the pathogenic mechanisms of nasal polyps development among asthmatics and directing future researches of disease etiology.

\section{ACKNOWLEDGEMENTS}

This work was supported by Grant Number M1-0302-00-0073 from the Korea Science and Engineering Foundation funded by the Korean government (Ministry of Education, Science and Technology; No. 2009-0080157), a Priority Research Centers Program through the NRF funded by the MEST (20090093822) and grant from the Korea Health 21 R\&D Project (A010249). 
1 Bernstein, J. M. \& Kansal, R. Superantigen hypothesis for the early development of chronic hyperplastic sinusitis with massive nasal polyposis. Curr. Opin. Otolaryngol. Head Neck Surg. 13, 39-44 (2005).

2 Kakoi, H. \& Hiraide, F. A histological study of formation and growth of nasal polyps. Acta Otolaryngol. 103, 137-144 (1987).

3 Larsen, K. The clinical relationship of nasal polyps to asthma. Allergy Asthma Proc. 17, 243-249 (1996).

4 Szczeklik, A., Nizankowska, E. \& Duplaga, M. Natural history of aspirin-induced asthma. AIANE Investigators. European Network on Aspirin-Induced Asthma. Eur. Respir. J. 16, 432-436 (2000).

5 Hershko, A. \& Ciechanover, A. The ubiquitin system. Annu. Rev. Biochem. 67, 425-479 (1998).

6 Ciechanover, A. The ubiquitin-proteasome proteolytic pathway. Cell 79, 13-21 (1994).

7 Palombella, V. J., Rando, O. J., Goldberg, A. L. \& Maniatis, T. The ubiquitin-proteasome pathway is required for processing the NF-kappa B1 precursor protein and the activation of NF-kappa B. Cell 78, 773-785 (1994).

8 Chen, Z., Hagler, J., Palombella, V. J., Melandri, F., Scherer, D., Ballard, D. et al. Signalinduced site-specific phosphorylation targets I kappa B alpha to the ubiquitin-proteasome pathway. Genes Dev. 9, 1586-1597 (1995).
9 Picado, C., Bioque, G., Roca-Ferrer, J., Pujols, L., Mullol, J., Benitez, P. et al. Nuclear factor-kappaB activity is down-regulated in nasal polyps from aspirin-sensitive asthmatics. Allergy 58, 122-126 (2003).

10 Takeno, S., Hirakawa, K., Ueda, T., Furukido, K., Osada, R. \& Yajin, K. Nuclear factorkappa $B$ activation in the nasal polyp epithelium: relationship to local cytokine gene expression. Laryngoscope 112, 53-58 (2002).

11 Ward, C. L., Omura, S. \& Kopito, R. R. Degradation of CFTR by the ubiquitinproteasome pathway. Cell 83, 121-127 (1995).

12 Lee, J. S., Kim, J. H., Bae, J. S., Kim, J. Y., Park, T. J., Pasaje, C. F. et al. Association analysis of UBE3C polymorphisms in Korean aspirin-intolerant asthmatic patients. Ann. Allergy Asthma Immunol. 105, 307-312 (2010).

13 Pasaje, C. F., Bae, J. S., Park, B. L., Jang, A. S., Uh, S. T., Kim, M. K. et al. Association analysis of DTD1 gene variations with aspirin-intolerance in asthmatics. Int. J. Mol. Med. 28, 129-137 (2011).

14 Crapo, R. O., Casaburi, R., Coates, A. L., Enright, P. L., Hankinson, J. L., Irvin, C. G. et al. Guidelines for methacholine and exercise challenge testing-1999. This official statement of the American Thoracic Society was adopted by the ATS Board of Directors, July 1999. Am. J. Respir. Crit. Care Med. 161, 309-329 (2000).

15 Prestridge, D. S. SIGNAL SCAN: a computer program that scans DNA sequences for eukaryotic transcriptional elements. Comput. Appl. Biosci. 7, 203-206 (1991).

16 Ambros, V., Bartel, B., Bartel, D. P., Burge, C. B., Carrington, J. C., Chen, X. et al. A uniform system for microRNA annotation. RNA 9, 277-279 (2003). 